\title{
Bending without breaking: Examining the role of attitudinal ambivalence in resisting persuasive communication
}

\author{
NICOLETTA CAVAZZA ${ }^{1 *}$ \\ AND FABRIZIO BUTERA ${ }^{2}$ \\ ${ }^{1}$ Università di Modena-Reggio Emilia, Italy \\ ${ }^{2}$ Université de Lausanne, Switzerland
}

\begin{abstract}
The present research aims at showing that ambivalence may serve an adaptive function: to preserve attitudes and to resist persuasion. In two experiments, participants were exposed to a counterattitudinal message attributed to an ingroup majority. Results of both experiments showed that individuals high in ambivalence changed toward the source more than individuals low in ambivalence at the direct level, while at the indirect level-where the link between attitudes and the source's message is less apparent-individuals low in ambivalence changed toward the source more than individuals high in ambivalence. Experiment 2 also showed that this effect is particularly true for high self-monitoring participants, thereby supporting a motivational interpretation of the effect. Copyright (C) 2007 John Wiley \& Sons, Ltd.
\end{abstract}

The aim of the present research is to propose that attitudinal ambivalence may serve an adaptive function: to preserve attitudes and to resist persuasion. Ambivalence has been described as a detrimental structural aspect of attitudes, in that it contributes to weakening attitudes (Petty \& Krosnick, 1995); indeed, high levels of ambivalence have been generally associated with low accessibility of attitudes, attitudinal moderation, low confidence, and low attitude-behavior coherence (Conner et al., 2002; Jonas, Broemer, \& Diehl, 2000). Attitudinal weakness is considered as a detrimental factor in the literature because it has been observed that the stronger the attitudes, the better they serve their fundamental function of object appraisal (Fazio, 2000). Indeed, several results have converged to show that attitudinal ambivalence forces individuals to start information processing all over again every time they face an attitude object (Broemer, 1988; Hanze, 2001; Van der Pligt, De Vries, Manstead, \& Van Harreveld, 2000). In particular, Maio, Bell, and Esses (1996) have shown

*Correspondence to: Dr Nicoletta Cavazza, Università di Modena-Reggio Emilia, via Allegri 9, 42100 Reggio Emilia, Italy. E-mail: cavazza.nicoletta@unimo.it 
that participants high in ambivalence are more involved in systematic processing and are more persuaded by strong than by weak arguments. With respect to these findings, Maio and Olson (2000) consider that the exact function of ambivalent attitudes is still an unsolved question: 'The functions fulfilled by ambivalent attitudes are particularly interesting because ambivalence should be aversive [...]. A challenge for future research is to further explore the functions fulfilled by ambivalent attitudes'. (p. 430). The present work aims at contributing to this exploration.

In fact, some studies have shown positive consequences of attitudinal ambivalence. Hanze (2001) showed that, in case of conflict, ambivalence reduces action readiness and promotes careful thinking about the attitude object in search of a suitable solution. Mucchi Faina, Costarelli, and Romoli (2002) pointed out that ambivalence toward the ingroup and the outgroup allows people to hide ingroup favoritism and to comply with the fairness norm. Furthermore, emotional ambivalence can enhance creativity (Fong, 2003) and functions as a motivational mechanism to affect smoking cessation (Lipkus, Green, Feaganes, \& Sedikides, 2001). These articles, however, did not claim that attitudinal ambivalence could be functional.

The present research aims at contributing to the debate on the function of ambivalent attitudes with the following proposition: Ambivalent attitudes could be in fact highly adaptive because the coexistence of positive and negative components allows people to express their position by putting forward the component that best fit the specific normative context (i.e., the norm shared by the immediately relevant majority), with no need to change or to feel inappropriate. For example, Monica-who holds ambivalent attitudes toward traffic restrictions-is perfectly able to contend that the level of pollution is now too high and traffic restrictions should be implemented, when talking about the children's health at kindergarten, but also to contend that living in cities is absolutely impossible without a car when discussing with a group of commuters. Ambivalence allows her to participate in both discussions without changing her general attitude. In other words, the structural flexibility of ambivalent attitudes would be a strength rather than a weakness.

In the perspective of attitudes-as-construction models (Schwartz, 2000; Wilson \& Hodges, 1992), there may be other cases in which attitudes are flexible and context-sensitive. These authors conceive attitudes as temporary evaluative judgments that individuals construct on the spot from accessible information. In particular, people may have more than one appraisal of the same attitude object-an implicit attitude and an explicit one-and they express the most accessible one (i.e., dual attitudes, Wilson, Lindsey, \& Schooler, 2000). Indeed, people are often unaware of the existence of the implicit attitude associated to the explicit one; according to the dual-attitude model (Wilson et al., 2000), when they are aware, they may view it as illegitimate or unwanted and may be motivated to override it with the explicit attitude (the authors call this case 'motivated overriding'). Thus, Wilson et al. explicitly differentiate dual attitudes from ambivalent attitudes, pointing out that when people are ambivalent they are aware of having different evaluations of the same attitude object but they view both as legitimate and compelling.

\section{ATTITUDINAL AMBIVALENCE AND ATTITUDE CHANGE}

Petty and Krosnick (1995) have proposed that attitudes can be considered as strong attitudes when they are persistent over time, resistant to persuasion, and they have an impact on thoughts and behavior. In the present research we will focus on the second characteristic, the resistance to persuasion attempts, since it is particularly relevant to study our general hypothesis that ambivalent attitudes can serve as a protection against pressure to change. The relevant literature is not unanimous in describing whether 
ambivalent attitudes are more or less permeable to persuasive communication than less ambivalent attitudes. In their review, Jonas et al. (2000) have formulated the hypothesis that ambivalent attitudes would be more resistant to persuasion, since they already contain in their structure elements consistent with the position maintained by the persuasive message. This is consistent with Eagly, Chen, Chaiken, and Shaw-Barnes' (1999) position. On the contrary, work by Armitage and Conner (2002) and by Bassili (1996) has argued that ambivalent (vs. nonambivalent) participants are more influenced by a persuasive message. However, Maio et al.'s results (1996) revealed that ambivalent participants were indeed more influenced by a persuasive message than nonambivalent participants, but only with strong arguments. Additionally, Broemer's work (2002) also showed this difference, but only when persuasive communication was constructed with a negatively framed message.

The above contradiction might be due to a differential 'normativity' of the persuasive messages. For instance, Hodson, Maio, and Esses (2001), who gave their participants consensus information (the majority's norm), showed that participants with high ambivalence scores shifted their position toward the majority's position (be it pro or con), whereas participants with low ambivalence scores shifted away from the majority. Furthermore, Bell and Esses (2002) found that ambivalent participants polarized their attitudes toward Native people in Canada as a consequence of message exposure only when they were led to believe that ambivalence is something bad, but not when ambivalence was framed as something good. It therefore appears difficult, on the basis of the above evidence, to contend that ambivalent attitudes are easier to influence and thereby weaker. It is possible, indeed, that the change sometimes observed in ambivalent individuals is in fact an opportunity they take to adapt to the normative context, without a real change in the overall attitudinal structure. In other words, it is possible that ambivalent individuals use a sort of compliance in order to manifest their agreement and at the same time to avoid a more structural change. This is not to say that resistance to change is adaptive per se: For example, a heavy smoker resisting a public health advertisement urging that smoker to quit might seem to be engaging in the opposite of an adaptive behavior. However, we hypothesize here that ambivalence might be used to adapt to the social environment, in a way that allow respecting the normative context while avoiding a deep change, one that involves both direct and indirect attitudes.

\section{DIRECT AND INDIRECT ATTITUDE CHANGE}

In order to address the difficulty of interpreting the meaning of change in highly ambivalent individuals, it was necessary to measure attitude change both at the direct and at the indirect level. Indeed, it is quite easy for individuals to comply (because they want to follow the norm) or to resist (because they want to show independence) to a source of influence at the direct level, that is, directly on the topic contained in the influence message. When people are asked to express their attitude toward the message topic, most of the time they can control their answer as a function of the normative context (Moscovici, 1980). However, it is more difficult for individuals to control their answer at the indirect level, that is, on a topic related to the influence message, underlain by the same general attitude, but not recognizable as a part of the influence message. This distinction has been successfully applied in several lines of research in the area of social influence and persuasion, as for instance in Alvaro and Crano (1997: Gays in the military and gun control), Mackie (1987: public disclosure of the names of juvenile convicts and protection of the rights of victims), and Pérez and Mugny (1987: abortion and contraception). See also Crano and Prislin (2006) for a recent discussion. Common features of these studies are that (a) the two 
measures are underlain by the same general attitude, (b) pretest has shown a significant correlation (between .30 and .60), and (c) one is contained in the influence message and the other is not.

We adopted this distinction to study direct and indirect attitude change in individuals high and low in ambivalence. It is important to note that the direct versus indirect distinction does not imply the same stakes as the explicit versus implicit distinction (e.g., Gawronski \& Bodenhausen, 2006), although they both address the problem of unobtrusively assessing attitudes. While the latter aims at comparing conscious versus unconscious attitudes, the direct-indirect distinction allows comparing attitudes toward themes directly mentioned by the influence source with attitudes toward themes not mentioned by the influence source, but underlain by the same general attitude (i.e., Wood, Lundgren, Ouellette, Busceme, \& Blackstone, 1994).

\section{DIFFERENTIAL DIRECT AND INDIRECT CHANGE OF INDIVIDUALS HIGH AND LOW IN AMBIVALENCE}

If it is true that ambivalence can be adaptive, we should show that highly ambivalent individuals may be strong in situations where individuals low in ambivalence are vulnerable. An interesting situation to study this idea is what scholars of conflict elaboration theory have termed normative conflict (e.g., Pérez \& Mugny, 1996). Normative conflict refers to situations where individuals find themselves in disagreement with the position of the majority of their ingroup, that is, situations where their attitude conflicts the norm. The prediction of the conflict elaboration theory is that when an individual cannot comply with the ingroup majority — say, because one has already revealed one's attitude or because one is committed to one's position-direct change would not be observed (for consistency reasons), but instead indirect change would take place, in order to restore similarity with the ingroup majority. This prediction has been successfully tested both with natural groups (e.g., Sanchez-Mazas, Mugny, \& Jovanovic, 1996; see Pérez \& Mugny, 1996, for an account in English) and with minimal groups (e.g., Muñoz, Falomir, Invernizzi, \& Leuenberger, 2000). These results are consistent with work documenting that the discrepancy between own attitude and the ingroup norm can lead to latent (e.g., Devine, Monteith, Zuwernik, \& Elliot, 1991; Dovidio \& Gaertner, 1986) and persistent change (e.g., Stangor, Sechrist, \& Jost, 2001).

The normative conflict situation is particularly relevant for individuals low in ambivalence. Indeed, when confronted with a counter-attitudinal message formulated by the ingroup majority, their clear, uniform, attitude should lead these individuals to resist change at the direct level and to be consistent with their own position, more so than highly ambivalent individuals who should have no problem in complying with the ingroup majority at this level; however, disagreement with the ingroup majority is a difficult position to hold and should result in more indirect change for individuals low in ambivalence than for highly ambivalent individuals, who do not need to resist at the direct level and thereby have a lower need to change at the indirect level. This idea relies on the principle that resistance at one level will displace influence at another level, as argued by several lines of research on social influence (Moscovici, 1980), conflict elaboration (Pérez \& Mugny, 1996), social cognition (Wegner, Schneider, Carter, \& White, 1987), and intergroup relations (Dovidio \& Gaertner, 1986). In sum, we hypothesize that, confronted to a counter-attitudinal message formulated by the ingroup majority, individuals high in ambivalence should change toward the source more than individuals low in ambivalence at the direct level, while at the indirect level individuals low in ambivalence should change toward the source more than individuals high in ambivalence. In other words we predict an interaction effect between levels of ambivalence and levels of attitude change. 


\section{EXPERIMENT 1}

\section{Method}

\section{Participants}

One-hundred and fifty-five 2nd-year communication sciences students at Bologna University and Modena-Reggio Emilia University volunteered for this experiment. Forty-seven were men and 108 women with a mean age of $21.82(S D=2.36)$. The effect of sex and that of university have been tested in all analyses; they did not yield any significant main or interaction effects and therefore will not be presented.

\section{Materials and Procedure}

Participants were asked to fill in two separate questionnaires at the beginning of a regular course. Two experimenters stressed the fact that the two booklets corresponded to two different studies (and in fact they appeared very different in aspect), carried out by the two different researchers. The first, pretest, questionnaire was presented as a survey on different topics debated in social life; it contained 20 items on various topics such as 'pollution is mainly caused by industries' and 'euthanasia is an immoral practice'. Participants responded on seven-point scales ranging from 'completely disagree' to 'completely agree'. In this questionnaire were embedded the two items designed to measure both the direct and indirect initial attitude (see below). Then, the participants answered the second booklet, which contained four sections. The first section just contained 14 personality items meant to function as a distractor.

The second section was devoted to the measurement of ambivalence toward traffic restrictions as a solution to pollution. In line with the multicomponent perspective on attitudes (Zanna \& Rempel, 1988), ambivalence was measured through a modified version of the open-ended procedure devised by Bell, Esses, and Maio (1996, see also Esses \& Maio, 2002), whereby affective and cognitive components of ambivalence were assessed. Although the Bell et al. (1996) task consisted of a series of open-ended questions asking participants to list adjectives (see Esses, Haddock, \& Zanna, 1993) and emotions related to the target issue, a pilot study $(N=73)$ conducted with a sample of students similar to the one used in the present experiment showed that these students tend to display an excessive rate of nonresponses. Therefore we preferred to transform the Bell et al. (1996) task into a selection task. Twenty adjectives (10 positive and 10 negative), derived from the above-mentioned pilot study, were presented on a page. Participants were asked to select those that they would associate with the topic of traffic restrictions. On a separate page, 20 emotions (10 positive and 10 negative), also derived from the pilot study, were presented and participants had to select those that they experienced when they thought about the topic. After choosing items for a particular component, participants were asked to return to their list and to assign a valence (favorability rating) to each of their responses. Valences ranged from -3 (extremely negative) to +3 (extremely positive). For emotions as well as for adjectives, positive dimension scores were obtained by summing the positive valences across the items listed; negative dimension scores were computed by summing the negative valences (see below for the exact formula for computing the ambivalence scores).

In the third section, participants were exposed to the persuasive message, framed as the result of a survey on the relationship between traffic restriction and pollution reduction, carried out among communication sciences students (i.e., the participants' ingroup). The results of this fictitious survey 
allegedly showed that the majority of respondents expressed a strong consensus on three arguments summarizing the belief that traffic restriction is not at all related to the pollution reduction (e.g., 'Traffic is not the main source of environmental damage in urban areas'). On the basis of a pilot study (see below) we knew that this position would be counter-attitudinal for the studied population. Moreover, participants for whom the message was not counter-attitudinal, based on the pretest direct attitude, were selected out. Twenty-four participants were thus excluded and our final sample consisted of 131 participants.

Finally, the fourth section was devoted to the post-test measure of the direct and indirect attitude items, embedded in a series of seven items on the importance of the topic proposed in the persuasive message. They answered on a 21-point scale in order to prevent the participants from remembering the exact value of their pretest answer. When they handed in the two booklets, the participants were thanked and debriefed.

\section{Attitudes and Attitudinal Ambivalence}

Attitudes: Pilot study. Direct attitudes consisted of the item 'Traffic-restrictive policies are useful to reduce pollution level in cities', whereas indirect attitude was represented by the item 'Using Diesel oil should be forbidden because of its polluting effects'. These two items were chosen on the basis of a further pilot study, also carried out with communication sciences students $(N=40)$, in which participants expressed their opinions on the same attitude items on seven-point scales ranging from 'completely disagree' to 'completely agree'. A correlation matrix was computed for all items and the above two were selected because their correlation was $r(40)=.40, p<.05$. Means showed that participant were overall in favor of both items $\left(M_{\mathrm{dir}}=6.02, S D_{\mathrm{dir}}=1.41\right.$ and $M_{\text {indir }}=4.26$, $\left.S D_{\text {indir }}=1.91\right)$.

Attitudinal ambivalence. To calculate ambivalence, the Bell et al. (1996) formula was applied (see also Esses \& Maio, 2002) to emotions as well as adjectives: $P+N-2|P-N|+36$, where $P=$ the positive dimension score, $N=$ the absolute value of the negative dimension score, and 36 is a constant that is added to preclude negative ambivalence scores. These calculations were performed for both adjectives and emotions separately and then the ambivalence scores for each one of them were averaged to compute the overall ambivalence score. Table 1 presents the main descriptive statistics for the three scores. The overall ambivalence score was dichotomized on the basis of the median $(\mathrm{Mdn}=32.50)$ in order to separate the highly ambivalent participants $(M=36.82, S D=3.64)$ from the less ambivalent participants ${ }^{1}(M=28.09, S D=4.27), F(1,129)=159.24, p<.001$.

\section{Results}

\section{Initial Attitude}

On the pretest direct attitude measure, participants appeared to be in favor of the fact that 'Today's pollution in cities necessitates traffic-restrictive solutions' $(M=5.97, S D=1.08)$. On the pretest

\footnotetext{
${ }^{1}$ Several authors have pointed out that dichotomizing quantitative variables can lead to introducing random error and eventually biases in the findings (e.g., MacCallum, Zhang, Preacher, \& Rucker, 2002). In this article, we have kept an ANOVA approach, as commonly practiced in recent attitude research (e.g., Bell \& Esses, 2002; Haddock, 2003), because means are more illustrative of the differences in attitude change on the direct and the indirect level. However, we have checked the reliability of the predicted interaction with a regression analysis as well, for both experiments (see Footnotes 2 and 3).
} 
Table 1. Descriptive statistics for ambivalence scores and intercorrelations (experiment 1)

\begin{tabular}{|c|c|c|c|c|c|}
\hline & \multirow[b]{2}{*}{$M$} & \multirow[b]{2}{*}{$S D$} & \multirow[b]{2}{*}{ Min-max } & \multicolumn{2}{|c|}{ Correlations } \\
\hline & & & & 1 & 2 \\
\hline 1. Adjectives & 32.05 & 8.94 & $6-61$ & & \\
\hline 2. Emotions & 33.19 & 5.26 & $14-48$ & $+.33^{* *}$ & \\
\hline 3. Overall ambivalence & 32.19 & 5.73 & $10.50-50.50$ & $+.91^{* *}$ & $+.70^{* *}$ \\
\hline
\end{tabular}

Note: ${ }^{* *}$ Correlation is significant at the .001 level.

indirect attitude, participants agreed with the statement 'Using Diesel oil should be forbidden because of its polluting effects' $(M=4.50, S D=1.80)$.

In order to avoid confounding attitudinal ambivalence and initial attitude, the difference in initial attitude between participants high and low in ambivalence was tested. ANOVAs on both direct and indirect attitude with ambivalence as a between-subjects factor yielded no significant effects (all $p s>10)$.

\section{Attitude Change}

Pretest and post-test attitude was measured on different scales; thus the 21-point post-test score was recoded to obtain a seven-point scale such that 1,2, and 3 correspond to $1 ; 4,5,6$ correspond to 2; 7, 8, 9 correspond to 3 and so on. Two attitude change scores were computed, both for direct and indirect attitude, by subtracting the pretest from the post-test, so that a negative score indicates an influence of the source's position. A 2 (level of ambivalence: high vs. low) $\times 2$ (level of influence: direct vs. indirect) mixed ANOVA design with repeated measures on the second factor was performed. The main effect of attitude level appeared to be significant, $F(1,129)=9.82, p<.05, \eta^{2}=.07$, indicating that direct change toward the source $(M=-0.49, S D=1.18)$ was larger than indirect change $(M=-.01$, $S D=1.35)$. The main effect of ambivalence level was not significant $(p>.10)$. Importantly, results, presented in Figure 1, showed the hypothesized interaction effect ${ }^{2}, F(1,129)=4.68, p<.05, \eta^{2}=.035$, confirming that the direct attitude change was oriented toward the source's position more for highly ambivalent participants $(M=-0.66, S D=1.22)$ than for participants low in ambivalence $(M=-0.30$, $S D=1.11)$, whereas the indirect change was oriented toward the source's position more for the less ambivalent participants $(M=-0.15, S D=1.37)$ than for the more ambivalent ones $(M=0.11$, $S D=1.32$ ).

\section{Discussion}

The results of the present experiment showed the relevance of our hypothesis. The predicted interaction between level of ambivalence and level of influence was significant. These results suggest that, in line with the normative conflict hypothesis (Pérez \& Mugny, 1996), at the direct level participants low in ambivalence may have used their attitudinal coherence to resist the counter-attitudinal message

\footnotetext{
${ }^{2}$ In order to check that the dichotomization has not biased the results of the present analysis, we have tested the predicted interaction by a regression analysis entering the ambivalence score as a predictor of the difference between the direct change and the indirect change scores. Results showed that this model accounted for significant variance, $R^{2}=0.04, F(1,129)=4.93$, $p<.05$, and confirmed that the difference between the two scores depended on the level of the ambivalence score, $\beta=-.19$, $t=2.22, p<.05$.
} 


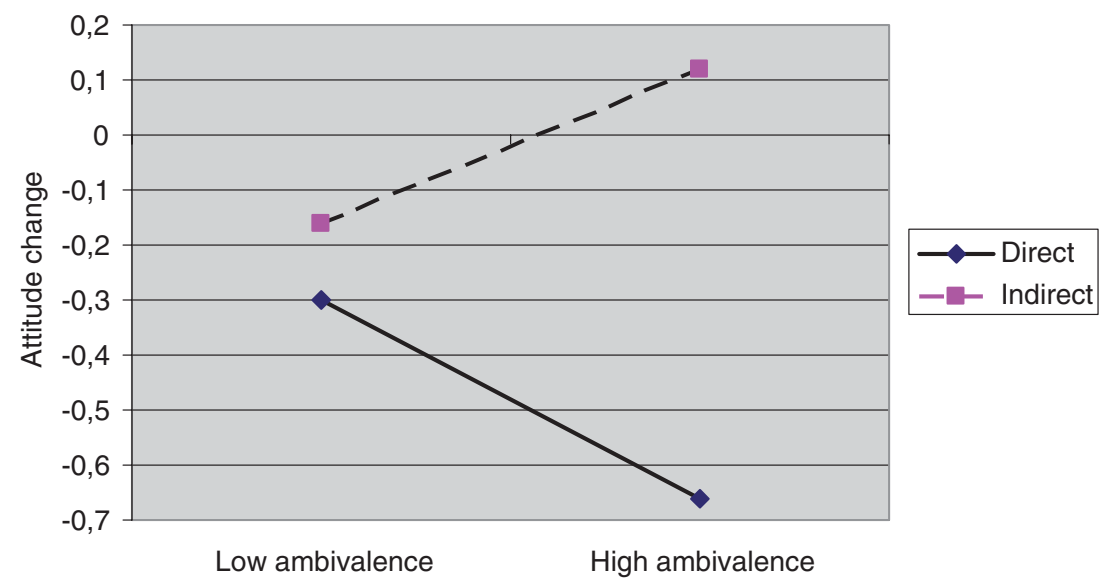

Figure 1. Experiment 1: Mean attitude change (lower means indicate more influence)

proposed by the ingroup majority more than participants high in ambivalence, while at the indirect level, where the link with the source's message is less apparent, participants low in ambivalence shifted toward the source's position more than participants high in ambivalence.

The above analysis implies that the observed effects rely upon the participants' concern for the normative demands of being confronted to the ingroup majority. If this motivational explanation holds true, the obtained pattern of result should be particularly apparent for those individuals who are the most concerned about the demands of the social situation, those who have a strategic approach to self-presentation. An effective way to test this hypothesis would be to inspect the moderating role of self-monitoring (Snyder, 1974). Indeed self-monitoring refers to 'individual differences in the extent to which individuals can and do monitor their self-presentation, expressive behavior, and nonverbal affective displays' (Snyder, 1974, pp. 526-527). In other words, high self-monitors are the people who are the most concerned with the demands of social situations: DeBono (1987) found that high (vs. low) self-monitors are more persuaded by a normative (vs. value based) message and he interpreted this result as an evidence of the social adaptive function of attitude for this kind of individuals. Thus, in experiment 2 we will test the hypothesis that the dynamics observed in experiment 1 will be more pronounced for high self-monitors than for low self-monitors.

\section{EXPERIMENT 2}

\section{Method}

\section{Participants}

One-hundred and fifty-one students at Modena-Reggio Emilia University volunteered for this experiment. Forty-four were men and 104 women ( 3 did not answer the question) with a mean age of $21.09(S D=3.22)$. On the basis of the pretest direct attitude (see below), the participants for whom the message was not counter-attitudinal were selected out. Forty-four participants were thus excluded and 
our final sample consisted of 106 participants. The effect of sex has been tested in all analyses; it did not yield any significant main or interaction effects and therefore will not be presented.

\section{Materials and Procedure}

The procedure of the present experiment was identical to the one followed in experiment 1 . However, one main difference, as compared to experiment 1, was introduced: The personality scale in the first section was no longer a filler questionnaire but contained the 25 items of the self-monitoring scale (Italian validation by Forzi, Arcuri, \& Kodilja, 1987).

\section{Attitudes}

Again we used 'Traffic-restrictive policies are useful to reduce pollution level in cities' and 'Using Diesel oil should be forbidden because of its polluting effects' as direct and indirect items.

\section{Attitudinal Ambivalence}

Table 2 presents the main descriptive statistics for the three ambivalence scores, computed as in the previous experiment. The overall ambivalence score was again dichotomized on the basis of the median $(\mathrm{Mdn}=22.00)$ in order to separate the highly ambivalent participants $(M=26.40, S D=3.78)$ from the less ambivalent participants $(M=17.28, S D=4.11), F(1,104)=140.81, p<.001$.

\section{Self-Monitoring Scale}

We measured self-monitoring orientation through the self-monitoring scale (Snyder, 1974), in the Italian version translated and validated by Forzi et al. (1987). It consisted of 25 balanced items with a five-point response scale ranging from 1 'it absolutely does not describe my behavior' to 5 'it completely describes my behavior'. We calculated an overall index of self-monitoring $(\alpha=.72)$ as the mean of the 25 items of the scale. Then we splitted the sample on the mid-point of the scale (3), which resulted in 69 low self-monitoring participants $(M=2.59, S D=0.27)$, those the least concerned with the demands of social situations, and 37 high self-monitoring participants $(M=3.29, S D=0.30$, $F(1,104)=146.98, p<.001)$, the most concerned.

Table 2. Descriptive statistics for ambivalence scores and intercorrelations (experiment 2)

\begin{tabular}{lccccc}
\hline & & & & \multicolumn{2}{c}{ Correlations } \\
\cline { 3 - 5 } & $M$ & $S D$ & Min-max & 1 & 2 \\
\hline 1. Adjectives & 20.87 & 8.78 & $0-49$ & & \\
2. Emotions & 22.81 & 5.89 & $2-37$ & $+.33^{* *}$ & $+.73^{* *}$ \\
3. Overall ambivalence & 21.84 & 6.04 & $6-42.50$ & $+.88^{* *}$ & \\
\hline
\end{tabular}

Note: ${ }^{* *}$ Correlation is significant at the .001 level. 


\section{Results}

\section{Initial Attitude}

On the pretest direct attitude measure, participants clearly agreed with the statement 'Traffic-restrictive policies are useful to reduce pollution level in cities' $(M=5.45, S D=1.15)$ and were slightly in favor of the fact that 'Using Diesel oil should be forbidden because of its polluting effects' $(M=4.25$, $S D=1.84$ ). In order to avoid confounding attitudinal ambivalence, self-monitoring orientation and initial attitude, two analyses of variance (ANOVAs) on both direct and indirect attitude, with ambivalence and self-monitoring orientation as between-participants factors were conducted. Neither of them yielded significant effects (all $p s>.10$ ).

It should also be noted that self-monitoring and ambivalence are not correlated $r(106)=-.006$, n.s. This might be due to the fact that self-monitoring is conceptualized as a personality trait, whereas ambivalence is object-specific; for instance, the same high self-monitoring person may hold univalent attitudes on some objects and ambivalent attitudes on others.

\section{Attitude Change}

Again post-test attitude measures have been transformed in a 7-point scale by recoding the 21-point scale. Two attitude change scores were computed, both for direct and indirect attitude, by subtracting the pretest from the post-test, so that a negative score indicates an influence of the source's position. A 2 (level of ambivalence: high vs. low) $\times 2$ (self-monitoring orientation: high vs. low) $\times 2$ (level of influence: direct vs. indirect) mixed ANOVA with repeated measures on the third factor was performed. Results yielded a main effect of attitude level, $F(1,102)=10.03, p<.05, \eta^{2}=.09$, and two significant interactions: A two-way interaction between ambivalence and level of attitude change, $F(1,102)=7.30, p<.05, \eta^{2}=.07$, as in experiment 1 , and the hypothesized three-way interaction between the three factors ${ }^{3}, F(1,102)=6.69, p<.05, \eta^{2}=.06$.

Table 3 shows means and standard deviations for all conditions. The three-way interaction pointed out that the interaction effect between level of ambivalence and level of attitude change was, as expected, significant for high self-monitoring respondents, $F(1,35)=17.26, p<.001$, whereas it was not for low self-monitors, $F(1,67)<1$. Results for high self-monitors revealed that direct attitude change toward the source's position was more pronounced for high-ambivalence participants $(M=-2.10, S D=1.48)$ than for low-ambivalence participants $(M=-0.29, S D=1.26)$, whereas the reverse pattern emerged for indirect change: $\left(M_{\text {high ambivalence }}=-0.15, S D=0.99, M_{\text {low }}\right.$ ambivalence $\left.=-0.65, S D=1.45\right)$, thereby replicating the results found in experiment 1 . These dynamics are depicted in Figure 2.

\section{DISCUSSION}

The second experiment replicated the significant interaction effect between level of ambivalence and level of influence already found in experiment 1 . In line with the specific hypotheses of the present experiment, the results confirmed the moderating role of self-monitoring orientation in the above

\footnotetext{
${ }^{3} \mathrm{~A}$ hierarchical regression analysis entering the ambivalence and the self-monitoring scores in the first step and the interaction term in the second step as predictors of the difference between the direct change and the indirect change scores showed that the first model accounted for significant variance, $R^{2}=0.07, F(2,103)=3.71, p<.05$ and confirmed that the difference between the two scores depended on the level of the ambivalence score, $\beta=-.24, t=2.50, p<.05$. The second model increased significantly the portion of explained variance, $R_{\text {change }}^{2}=0.031, F(3,102)=3.58, p<.02$; the effect of ambivalence level disappeared in favor of the interaction between the two predictors, $\beta=-1.28, t=1.77, p=.08$.
} 
Table 3. Mean attitude change (and standard deviation) as a function of self-monitoring orientation, level of ambivalence, and level of attitude change (experiment 2)

\begin{tabular}{llcr}
\hline & & \multicolumn{2}{c}{ Self-monitoring orientation } \\
\cline { 3 - 4 } Ambivalence & Level of attitude change & High & \multicolumn{1}{c}{ Low } \\
\hline High & Direct & $-2.10(1.48)$ & $-0.82(1.99)$ \\
Low & Indirect & $-0.15(0.98)$ & $-0.21(1.63)$ \\
& Direct & $-0.29(1.26)$ & $-0.55(1.54)$ \\
& Indirect & $-0.64(1.45)$ & $0.00(1.39)$
\end{tabular}

Note: Negative scores indicate a change in the direction advocated by the message.

effects: It was shown that, when high in self-monitoring, participants high in ambivalence obtained change scores that approached the source's position more than participants low in ambivalence at the direct level, while at the indirect level the difference between participants high and low in ambivalence followed the reverse pattern. These dynamics did not appear for participants low in self-monitoring. This three-way interaction supports our motivational interpretation that the opposite pattern of results for high and low ambivalence participants under normative conflict is really due to a strategic adaptation to the normative demands of the relationship with the ingroup majority, as these dynamics appear particularly for those participants who are the most sensitive to the social context (the high self-monitors). The low self-monitors have a lower need to manage their self-presentation in accordance with the ingroup stance, which may explain why their ambivalence level does not determine their reaction to the persuasive message.

\section{GENERAL DISCUSSION}

The two studies presented in this article showed convergent evidence to support the hypothesis that, in front of a counter-attitudinal message proposed by an ingroup majority, highly ambivalent people shift

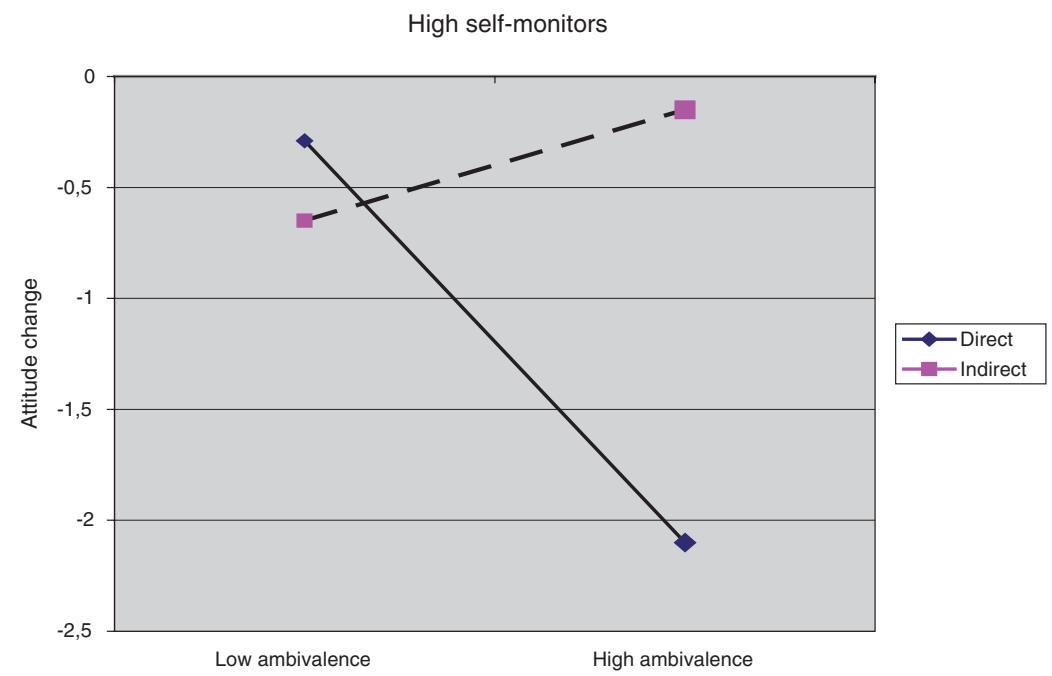

Figure 2. Experiment 2: Mean attitude change (lower means indicate more influence) for high self-monitors 
their position toward the influence source to a greater extent than less ambivalent people at the direct level, but that at the indirect level highly ambivalent people resist influence more than less ambivalent people. Both studies presented here suggest that ambivalent attitudes can be functional in a context of persuasive normative communication. The coexistence of pro and con components within the same attitude structure allowed highly ambivalent participants to solve the normative conflict at the direct level, by expressing one of the components, that in the direction of the ingroup majority, more so than participants low in ambivalence. At the indirect level, in turn, the impact of the influence source on participants high in ambivalence was thus reduced, as compared to participants low in ambivalence. Thus, paradoxically, manifest conformity allowed highly ambivalent participants to reduce latent change, comparatively to low-ambivalence participants.

These results constitute a contribution to Maio and Olson's (2000) question regarding the functions fulfilled by ambivalent attitudes. In fact, there are situations in which ambivalent attitudes are functional. Some of these functions have already been shown and tested in the literature (Fong, 2003; Hanze, 2001; Lipkus et al., 2001; Mucchi Faina et al., 2002). The present motivational explanation suggests that attitudinal ambivalence may be used to strategically avoid deep change. This idea is comforted by Maio and Haddock's (2004), statement: 'It is possible that social norms make it occasionally desirable to have high ambivalence in an attitude. Ambivalence may be desirable when an issue is controversial. In this situation, people who appear ambivalent may give the impression of being fair and knowledgeable. These individuals may also be inoffensive to others because they "agree" with everyone to some extent' (2004, p. 435).

The strategic function of ambivalent attitudes was further stressed by the moderating role of self-monitoring found in experiment 2. Indeed, it showed that a dispositional factor related to the sensitivity to social adjustment affected the way participants were influenced by the ingroup majority's message as a function of their ambivalence level. These findings are in accordance with Bell and Esses (2002), who described how individuals with ambivalent attitudes can modify the expression of their attitude in order to satisfy an internal motivation.

Three limitations should be noted. First, although attitude change varied in the predicted directions, the amplitude of attitude change itself is not very high in both studies. This could be due to the experimental context, which implied a paper-pencil task, in anonymous conditions, and in a collective testing situation. Further research in a more naturalistic setting, in which participants would be more involved in the expression of attitudes and more affected by normative conflict, might find greater attitude change effects. Second, the present studies have inspected the hypothesized effect by operationalizing the two levels of influence with the direct and indirect measures. Stronger evidence, however, could come from replicating these findings by operationalizing the two levels of influence in other ways, for instance by measuring attitudes at a private and a public level or at immediate and delayed phases (Moscovici, 1980). Finally, in our experiments the counter-attitudinal message was always negatively framed and therefore the results may not be generalizable to positively framed messages. We suspect, however, that a positive frame might weaken the observed effects because ambivalence involves a negativity bias, consisting of a stronger impact of negative information on overall evaluation (Broemer, 2002; Cacioppo, Gardner, \& Berntson, 1997).

Notwithstanding these limitations, we believe that the present research contributes to the attitudes literature in three ways. First, research that has addressed the relationship between attitudinal ambivalence and attitude change has generally studied it only at the direct level (e.g., Broemer, 2002; Hodson et al., 2001). The present research shows that articulating the direct and the indirect levels may show a hidden pattern of influence that might otherwise be overlooked. Second, literature on social influence and attitude change did address the question of the different levels of influence (Alvaro \& Crano, 1997; Pérez \& Mugny, 1987), but mainly studied it by focusing on source, message, and context variables. To the best of our knowledge, this is the first work that articulates a structural characteristic of 
attitudes, such as ambivalence, with levels of influence. Third, our results suggest that ambivalence might contribute to make attitudinal structure more flexible than does the absence of ambivalence. Indeed, the normative counter-attitudinal message did not result in a global structural change, but a superficial adaptation to the context, suggesting that people high in ambivalence would be able to activate the various components of their attitudes in a strategic way. Having a wider repertoire of responses is indeed a strength and not a weakness.

\section{ACKNOWLEDGEMENTS}

This work was supported by a Marco Polo grant. We express our gratitude to Chiara Calzoni, Chiara Dini, and Elisabetta Violi for collecting the data, and to Piergiorgio Corbetta, Céline Darnon, Juan-Manuel Falomir, Angelica Mucchi Faina, Dominique Muller, Caroline Pulfrey, Michele Roccato for comments on earlier drafts of this manuscript.

\section{REFERENCES}

Alvaro, E. M., \& Crano, W. D. (1997). Indirect minority influence: Evidence for leniency in source evaluation and counterargumentation. Journal of Personality and Social Psychology, 72, 949-964.

Armitage, C. J., \& Conner, M. (2002). Reducing fat intake: Interventions based on the Theory of Planned Behaviour. In D. Rutter, \& L. Quine (Eds.), Changing health behaviour: Intervention and research with social cognition models (pp. 87-104). Buckingham, England: Open University Press.

Bassili, J. N. (1996). Meta-judgmental versus operative indexes of psychological attributes: The case of measures of attitude strength. Journal of Personality and Social Psychology, 71, 637-653.

Bell, D. W., Esses, V. M., \& Maio, G. R. (1996). The utility of open-ended measures to assess intergroup ambivalence. Canadian Journal of Behavioral Science, 28, 12-18.

Bell, D. W., \& Esses, V. M. (2002). Ambivalence and response amplification: A motivational perspective. Personality and Social Psychology Bulletin, 28, 1143-1152.

Broemer, P. (2002). Relative effectiveness of differently framed health messages: The influence of ambivalence. European Journal of Social Psychology, 32, 685-703.

Broemer, P. (1988). Ambivalent attitudes and information processing. Swiss Journal of Psychology, 57, $225-234$.

Cacioppo, J. T., Gardner, W. L., \& Berntson, G. G. (1997). Beyond bipolar conceptualization and measures: The case of attitudes and evaluative space. Personality and Social Psychology Review, 1, 3-25.

Conner, M., Sparks, P., Povey, R., James, R., Shepherd, R., \& Armitage, C. J. (2002). Moderator effect of attitudinal ambivalence on attitude-behaviour relationships. European Journal of Social Psychology, 32, 705-718.

Crano, W. D., \& Prislin, R. (2006). Attitudes and persuasion. Annual Review of Psychology, 57, 345-374.

DeBono, K. G. (1987). Investigating the social-adjustive and value-expressive functions of attitudes: Implications for persuasion processes. Journal of Personality and Social Psychology, 52, 279-287.

Devine, P., Monteith, M., Zuwerink, J., \& Elliot, A. (1991). Prejudice with and without compunction. Journal of Personality and Social Psychology, 60, 817-830.

Dovidio, J., \& Gaertner, S. (1986). Prejudice, discrimination and racism. New York: Academic Press.

Eagly, A. H., Chen, S., Chaiken, S., \& Shaw-Barnes, K. (1999). The impact of attitudes on memory: An affair to remember. Psychological Bulletin, 125, 64-89.

Esses, V. M., Haddock, G., \& Zanna, M. P. (1993). Values, stereotypes, and emotions as determinants of intergroup attitudes. In D. M. Mackie, \& D. L. Hamilton (Eds.), Affect, cognition, and stereotyping: Interactive processes in group perception (pp. 137-166). San Diego, CA, US: Academic Press.

Esses, V. M., \& Maio, G. R. (2002). Expanding the assessment of attitude components and structure: The benefits of open-ended measures. European Review of Social Psychology, 12, 71-101. 
Fazio, R. H. (2000). Accessible attitudes as tools for object appraisal: Their costs and benefits. In G. R. Maio, \& J. M. Olson (Eds.), Why we evaluate? Functions of attitudes (pp. 1-36). London: Laurence Erlbaum Associates.

Fong, C. T. (2003). The effect of emotional ambivalence on creativity. Dissertation Abstract International, 64, 1746.

Forzi, I., Arcuri, L., \& Kodilja, R. (1987). Aspetti differenziali nella percezione di sè e processi attribuzionali [Differential aspects in self perception and attributional processes]. Reports of the institute of Psychology. Trieste: The University of Trieste.

Gawronski, B., \& Bodenhausen, G. V. (2006). Associative and propositional processes in evaluation: An integrative review of implicit and explicit attitude change. Psychological Bulletin, 132, 692-731.

Haddock, G. (2003). Making a party leader less of a party member: The impact of ambivalence on assimilation and contrast effects in political party attitudes. Political Psychology, 24, 769-780.

Hanze, M. (2001). Ambivalence, conflict and decision making: Attitudes and feelings in Germany towards NATO's military intervention in the Kosovo war. European Journal of Social Psychology, 31, 693-706.

Hodson, G., Maio, G. R., \& Esses, V. M. (2001). The role of attitudinal ambivalence in susceptibility to consensus information. Basic and Applied Social Pychology, 23, 197-205.

Jonas, K., Broemer, P., \& Diehl, M. (2000). Attitude ambivalence. European Review of Social Psychology, 11, $35-74$.

Lipkus, I. M., Green, J. D., Feaganes, J. R., \& Sedikides, C. (2001). The relationship between attitudinal ambivalence and desire to quit smoking among college smokers. Journal of Applied Social Psychology, 31, 113-133.

MacCallum, R. C., Zhang, S., Preacher, K. J., \& Rucker, D. D. (2002). On the practice of dichotomization of quantitative variables. Psychological Methods, 7, 19-40.

Mackie, D. M. (1987). Systematic and nonsystematic processing of majority and minority persuasive communications. Journal of Personality and Social Psychology, 53, 41-52.

Maio, G. R., Bell, D. W., \& Esses, V. M. (1996). Ambivalence and persuasion: The processing of messages about immigrant groups. Journal of Experimental Social Psychology, 32, 513-536.

Maio, G. R., \& Haddock, G. (2004). Theories of attitude. Creating a witches' brew. In G. Haddock, \& G. R. Maio (Eds.), Contemporary perspectives on the psychology of attitude. Hove and New York: Psychology Press.

Maio, G. R., \& Olson, J. M. (2000). Emergent themes and potential approaches to attitude function: The functionstructure model of attitudes. In G. R. Maio, \& J. M. Olson (Eds.), Why we evaluate: Functions of attitudes (pp. 417-442). Mahwah, NJ: Lawrence Erlbaum, Inc.

Moscovici, S. (1980). Toward a theory of conversion behaviour. In L. Berkowitz (Ed.), Advances in experimental social psychology (Vol. 13, pp. 209-239). New York: Academic Press.

Mucchi Faina, A., Costarelli, S., \& Romoli, C. (2002). The effect of intergroup context of evaluation on ambivalence toward the ingroup and the outgroup. European Journal of Social Psychology, 32, 247-259.

Muñoz, D., Falomir, J. M., Invernizzi, F., \& Leuenberger, S. (2000). Normative discrepancies and social discrimination change in an experimental group setting. International Review of Social Psychology, 13, 7-40.

Pérez, J. A., \& Mugny, G. (1987). Paradoxical effects of categorization in minority influence: When being an outgroup is an advantage. European Journal of Social Psychology, 17, 157-169.

Pérez, J. A., \& Mugny, G. (1996). The Conflict Elaboration Theory of Social Influence. In H. E. Witte, \& H. J. Davis (Eds.), Understanding group behavior (Vol. 2, Small Group Processes and Interpersonal Relations, (pp. 191-210). Mahwah, NJ: Lawrence Erlbaum Associates.

Petty, R. E., \& Krosnick, J. A. (1995). Attitude strength. Antecedents and consequences. Mahwah, NJ: Lawrence Erlbaum Associates.

Sanchez-Mazas, M., Mugny, G., \& Jovanovic, J. (1996). Conflit normatif et changement des attitudes intergroupes. [Normative conflict and the change of intergroup attitudes]. Revue Internationale de Psychologie Sociale, 8, 25-43.

Schwartz, N. (2000). Social judgment and attitudes: Warmer, more social, and less conscious. European Journal of Social Psychology, 30, 149-176.

Snyder, M. (1974). Self-monitoring of expressive behavior. Journal of Personality and Social Psychology, 30, 526-537.

Stangor, C., Sechrist, G., \& Jost, J. (2001). Changing racial beliefs by providing consensus information. Personality and Social Psychology Bulletin, 27, 486-496.

Van der Pligt, J., De Vries, N. K., Manstead, A. S. R., \& Van Harreveld, F. (2000). The importance of being selective: Weighing the role of attribute importance in attitudinal judgment. In M. P. Zanna (Ed.), Advances in experimental social psychology (Vol. 32, pp. 135-200). San Diego, CA, US: Academic Press. 
Wegner, D. M., Schneider, D. J., Carter, S. R., \& White, T. L. (1987). Paradoxical effects of thought suppression. Journal of Personality and Social Psychology, 53, 5-13.

Wilson, T. D., \& Hodges, S. D. (1992). Attitudes as temporary constructions. In L. L. Leonard, \& A. Tesser (Eds.), The construction of social judgments (pp. 37-65). Mahwah, NJ: Lawrence Erlbaum Associates.

Wilson, T. D., Lindsey, S., \& Schooler, T. Y. (2000). A model of dual attitudes. Psychological Review, 107, 101-126.

Wood, W., Lundgren, S., Ouellette, J. A., Busceme, S., \& Blackstone, T. (1994). Minority influence: A meta-analytic review of social influence processes. Psychological Bulletin, 115, 323-345.

Zanna, M. P., \& Rempel, J. K. (1988). Attitudes: A new look at an old concept. In D. Bar-Tal, \& A. Kruglanski (Eds.), The social psychology of knowledge (pp. 315-334). Cambridge: Cambridge University Press. 